\title{
Transradial Approach versus Anatomical Snuff Box Distal Radial Access for Coronary Procedures
}

\author{
Saeed Shalaby Montaser ${ }^{1}$, Ahmed Mohamed Emara ${ }^{1}$, Shehab Adel Eletriby ${ }^{2}$, Ahmed A. Tawfeek ${ }^{3}$ \\ ${ }^{1}$ Faculty of Medicine, Al-Menoufia University, Menoufia, Egypt \\ ${ }^{2}$ Faculty of Medicine, Ain Shams University, Cairo, Egypt \\ ${ }^{3}$ Department of Cardiology, Ahmed Maher Teaching Hospital, Cairo, Egypt \\ Email: Alsebaaiahmad@yahoo.com
}

How to cite this paper: Montaser, S.S., Emara, A.M., Eletriby, S.A. and Tawfeek, A.A. (2020) Transradial Approach versus Anatomical Snuff Box Distal Radial Access for Coronary Procedures. World Journal of Cardiovascular Diseases, 10, 716-730. https://doi.org/10.4236/wjcd.2020.1010069

Received: July 21, 2020

Accepted: October 23, 2020

Published: October 26, 2020

Copyright (c) 2020 by author(s) and Scientific Research Publishing Inc. This work is licensed under the Creative Commons Attribution International License (CC BY 4.0).

http://creativecommons.org/licenses/by/4.0/

\begin{abstract}
Background: Radial artery catheterization is a fundamental approach that is used as a procedural access in the different catheterization laboratories so our study is a comparison between distal radial artery approach and convential traditional transradial approach to explore the fesibility and safety of coronary angiography and percutanous coronary. Aim of the Work: The purpose of our study is a comparison between the conventional transradial approach versus distal transradial approach for diagnostic and interventional coronary procedures. Materials and Methods: This is a prospective study that included 60 patients who presented to the Cardiology departments in Ahmed Maher Teaching Hospital from December 2018 until October 2019 to perform planned Transradial Coronary Angiography and/or coronary intervention. The study is divided into two groups, group (A) included 30 patients who undergone the procedure through the distal radial approach (The Anatomical Snuffbox) and group (B) included 30 patients who undergone the procedure through the traditional Transradial approach. Results: Thrombosis and hospital stay are higher significant in radial group than distal radial group and patient satisfaction is higher significant in distal radial group than traditional Transradial while there is no significant difference between both groups as regard Success and failure rate of cannulation, bleeding, infection and duration of the procedure. Conclusion: coronary procedures by distal radial approach have minor access complication versus the conventional Transradial approach.
\end{abstract}

\section{Keywords}

Radial Artery, SnuffBox, Catheterization 


\section{Introduction}

Coronary angiography with or without PCI requires arterial access. The standard access sites are femoral and radial arteries. During the last decade, the refinement and miniaturization of stents permitted the use of guiding catheters with smaller diameters that were better suited for use through the (relatively small) radial artery, in parallel to the recent improvements in the procedural success of PCI with modern devices [1] [2].

The focus of attention is shifting from the technical success of the coronary intervention to the prevention of access site complications. As a result, there is a growing interest in an alternative to TFA [3]. Randomized controlled trials and a meta-analytic study have suggested that radial access for CAG and/or PCI is a safe and effective alternative to the femoral approach, while the radial technique is associated with a reduction in hemorrhagic entry site complications and permits earlier patient ambulation [3] [4].

Radial artery catheterization is a fundamental approach that is used as a procedural access in the different catheterization laboratories due to low prevalence of access-related complications [5] [6]. Feasibility and safety of this technique initially provoked some euphoria among some interventional specialists, but later there was a realization of disadvantages of Radial artery catheterization including radial artery spasm, vessel thrombosis and different types of wall lesions of the access artery. Traditionally, the optimal radial artery puncture site was considered to be at the distal third of forearm because of the superficial position of the artery close to the radial bone that facilitates puncture and following hemostasis. The preferred puncture site is about $2 \mathrm{~cm}$ proximal to the radial styloid. Although the pulse is often palpated more easily below this point, the artery is tortuous and below the flexor retinaculum. A more distal puncture will often do not permit the wire to pass [3] as shown in Figure 1.

Another site for the puncture is anatomical snuffbox where the artery lies closely to the skin along the surface of radio carpal joint that serves as "basement" [8].

The anatomical snuffbox is a hollow space on the radial side of the wrist when the thumb is extended; it is bounded by the tendon of the extensor pollicis longus posteriorly and of the tendons of the extensor pollicis brevis and abductor pollicis longus anteriorly. The RA crosses the floor that is formed by the scaphoid and the trapezium bones [9] as shown in Figure 2.

The distinctive feature of this area is its location distally to the superficial palmar branch of radial artery that communicates with superficial palmar arterial arch of ulnar artery and other feature of this area is surrounded by soft tissues of hand, which is essential for the adequate hemostasis [11].

Arterial wall damages in access site are multi-faceted: perforation and/or pulsatile hematoma (false aneurysm), injury of proximal major blood vessels, arteriovenous fistula. Post-catheterization radial artery occlusion (PCRAO) is the most common complication of radial access, it's reported by different authors to 


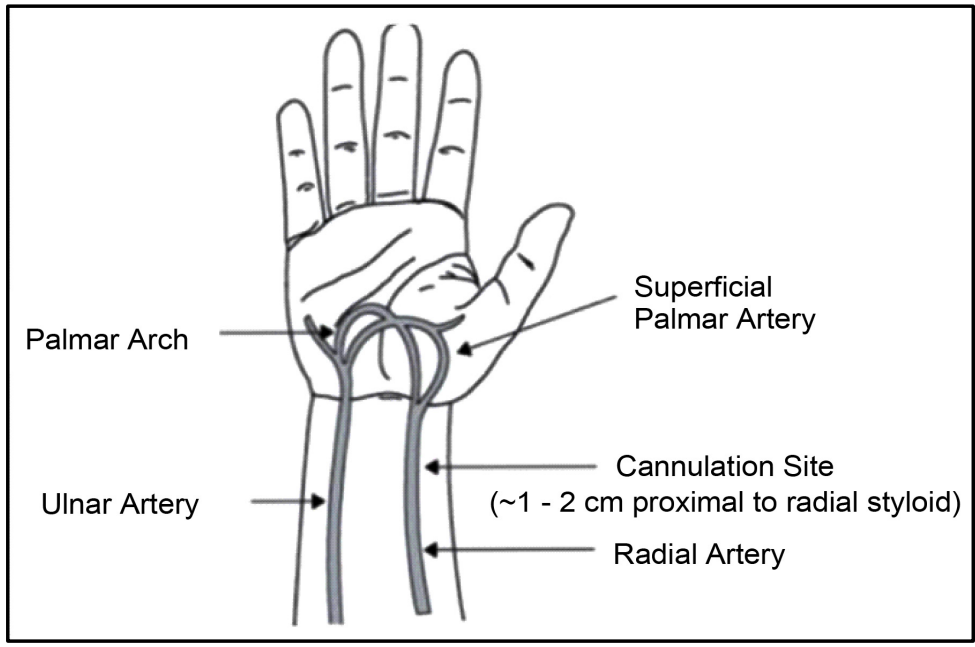

Figure 1. Puncture site of conventional radial approach [7].

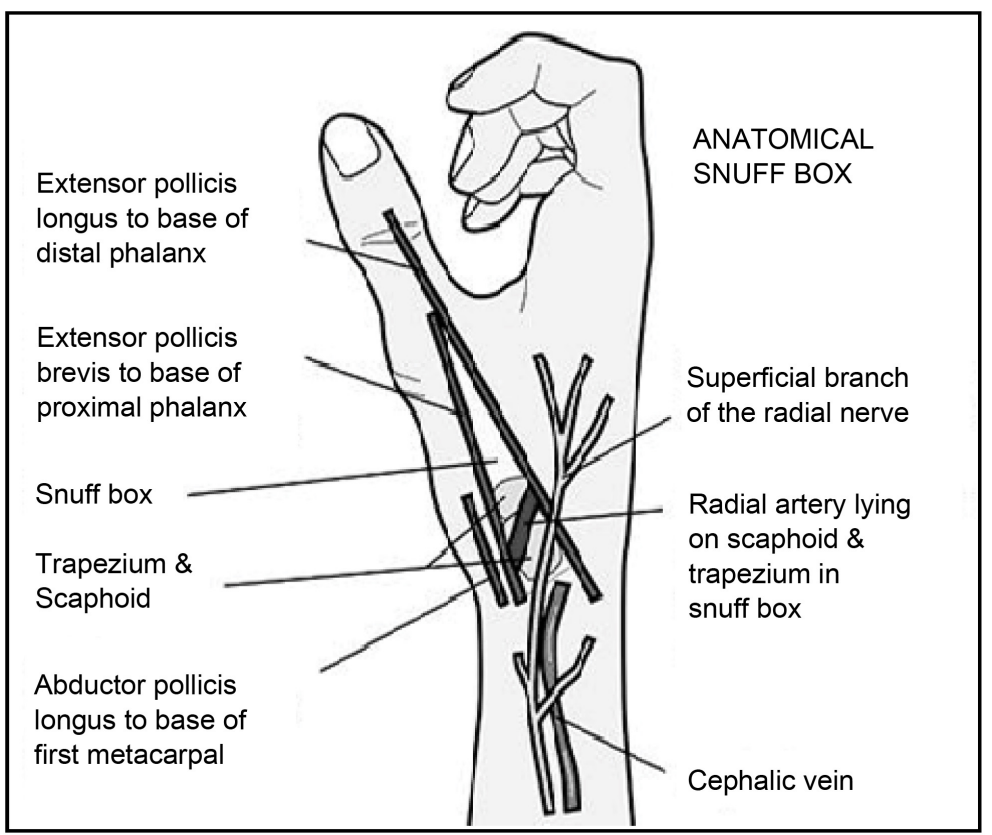

Figure 2. Anatomical snuff box Anatomy [10].

occur in $0 \%-10 \%$ of case, there are three fundamental causes of the access artery occlusion, arterial puncture, arterial catheterization and incorrect puncture hemostasis [12].

On the basis of observations, the suggestion that in case of total radial artery occlusion within the anatomical snuffbox (RAAS), the ante grade blood flow would be preserved through the superficial palmar arch, therefore the risk of thrombosis and extensive forearm radial artery occlusion would be minimized. Radial artery portion of the hand is surrounded by soft tissues that are elastic by nature; this leads to "non complete" artery compression with a hemostatic Bandage applied to this area. Combining this consideration with the aforementioned possibility of preserved ante grade blood flow in the superficial palmar arch 
makes to suggest lower risk of post-catheterization radial artery occlusion in this area [5].

The post-catheterization impairment of the radial artery does not manifest only with occlusion but also with stenosis. The pulsation over a length of the radial artery is preserved but its use as an access artery seems problematic [13].

\section{Methods}

This is a prospective randomized study that included 60 patients who presented to the Cardiac cath. Lab in Ahmed Maher Hospital from December 2018 until October 2019 to perform Transradial Coronary angiography and intervention.

The study divided in to two groups, Group (A) included 30 patients who undergone the procedure through the distal radial approach (The Anatomical Snuffbox), and Group (B) included 30 patients who undergone the procedure through the traditional Transradial approach.

Patients with past history of hand orthopedic surgery, past history of vascular hand surgery, past history of GABG using radial artery graft and patients with past history of complicated radial artery approach were excluded from the study.

Each patient was subjected to history as Age, gender, habits of medical importance, Full analysis of chest pain especially as regards type, duration, what increase and what decrease, risk factors as Previous ischemic events, Diabetes mellitus, hypertension, dyslipidemia, chronic kidney disease, peripheral vascular disease, cerebrovascular disease and obesity.

Clinical examination included general examination as $\mathrm{ABP}$ and heart rate, weight, height, body mass index and local examination.

Investigation as Twelve lead surface ECG, Echo_Doppler Study and Arterial Doppler Pre and post procedures

1) Procedure:

\section{- Distal transradial approach technique}

After receiving institutional review board approval, Patient demographics, procedural and radiographic metrics, and clinical data were recorded. Distal transradial approach technique Procedural consent, pre procedure testing, room setup, and post procedure assessment were performed. The right arm or the left arm is placed comfortably on a cushion on the right or left side of the patient, after disinfection, the patient is covered with a sterile drape. The operator took up a position near the patient's forearm for subcutaneous injection of $3 \mathrm{cc}$ xylocaine filling the Snuff Box area. To bring the artery to the surface of the fossa, the patient was asked to grip slightly his thumb under the other four fingers, with the hand slightly abducted. The RA was punctured with a $21 \mathrm{G}$ needle, under an angle of 45 degrees. The needle was directed to the point of strongest pulse, proximal in the anatomical snuffbox. After the successful puncture in the anterior wall of the RA, a small skin incision was made, followed by introduction of $6 \mathrm{~F}$ radial sheath. Subsequently underwent an administration of $200 \mathrm{mcg}$ of nitroglycerine and a weight-adjusted dose of heparin. The operator took up a 
position at the level of the patient's knees to manipulate the 0.35 wire and the coronary catheters to make the Coronary angiography and/or coronary intervention. After the procedure, the sheath is removed and pressure is held over the arteriotomy site to achieve hemostasis. Used TR-Band either Traditional band.

\section{- Conventional Transradial Catheterization}

Under sterile conditions, the radial artery is accessed with a 20- to 21-gauge needle, and a 5F-6F sheath is advanced into the artery over a wire using the Seldinger technique. Vasodilators (usually verapamil and nitroglycerin) are administered to reduce radial artery spasm, Hydrophilic sheaths were generally used to minimize trauma to the radial artery. An anticoagulant (usually unfractionated heparin) is given to prevent radial artery thrombosis; a guidewire is then advanced from the radial artery to the ascending aorta. Catheters are advanced over the guidewire and used for coronary angiography and/or coronary intervention. Specialized catheters shaped to aid in engaging the coronary arteries from the transradial approach have been developed, although traditional coronary catheters can also be used. After the procedure, the sheath is removed and pressure is held over the arteriotomy site to achieve hemostasis. Used TR-Band either Traditional band.

2) Follow up:

Arterial Doppler had been done pre procedural and post procedural for all the patients in the two groups to assess the flow through the Radial artery and to evaluate the post procedural complications.

3) Outcomes of the procedures in the two groups had been reviewed including:

Success and failure rate of cannulation. Post Catheterization Radial Artery Occlusion, Hematoma, Pulsatile hematoma, Infection, Arteritis, Dissection, and Rupture of access artery (perforation), Total duration of the procedure, Discharge time and satisfaction between groups.

\section{Statistical Methods}

Data collected throughout history, basic clinical examination, laboratory investigations and outcome measures coded, entered and analyzed using Microsoft Excel software. Data were then imported into Statistical Package for the Social Sciences (SPSS version 20.0) (Statistical Package for the Social Sciences) software for analysis. According to the type of data qualitative represent as number and percentage, quantitative continues group represent by mean $\pm S D$, the following tests were used to test differences for significance; Difference and association of qualitative variable by Chi square test (X2). Differences between quantitative independent groups by $t$ test. $\mathrm{P}$ value was set at $<0.05$ for significant results \& $<0.001$ for high significant result.

\section{Results}

All patients were subjected to history taking and full clinical examination, Radial 
artery Doppler pre procedural and post procedure was done, Coronary angiography was recorded and intervention was done, the data was collected and analyzed as follows:

Age distributed as $53.47 \pm 4.32$ ys and $53.07 \pm 4.412$ ys with no significant difference between groups as shown in Table 1 .

Group (A) included 30 patients out of them: 25 patients were males and 5 were females, whereas in group (B): 21 patients were males and 9 were females. There was no significant difference between groups regarding gender as shown in Table 2 and Figure 3.

There was no significant difference between groups regard risk factors. Group (A): were diabetic, 18 were dyslipidemia and 7 were hypertensive while in Group

Table 1. Comparison between two groups as regard age.

\begin{tabular}{ccccccccc}
\hline \multirow{2}{*}{ Groups } & \multicolumn{9}{c}{ Age } & & \multicolumn{2}{c}{ T-test } \\
\cline { 2 - 8 } & \multicolumn{3}{c}{ Range } & Mean & \pm & SD & t & P-value \\
\hline Snuff box (Group A) & 45 & - & 60 & 53.47 & \pm & 4.32 & & 0.791 \\
Radial (Group B) & 46 & - & 60 & 53.77 & \pm & 4.41 & & \\
\hline
\end{tabular}

Table 2. Comparison between two groups as regard gender.

\begin{tabular}{|c|c|c|c|c|c|c|c|}
\hline \multirow{3}{*}{ Gender } & & \multicolumn{6}{|c|}{ Groups } \\
\hline & & \multicolumn{2}{|c|}{$\begin{array}{l}\text { Snuff box } \\
\text { (Group A) }\end{array}$} & \multicolumn{2}{|c|}{$\begin{array}{c}\text { Radial } \\
\text { (Group B) }\end{array}$} & \multicolumn{2}{|c|}{ Total } \\
\hline & & $\mathrm{N}$ & $\%$ & $\mathbf{N}$ & $\%$ & $\mathbf{N}$ & $\%$ \\
\hline Female & & 5 & 16.7 & 9 & 30.0 & 14 & 23.3 \\
\hline Male & & 25 & 83.3 & 21 & 70.0 & 46 & 76.7 \\
\hline Total & & 30 & 100.0 & 30 & 100.0 & 60 & 100.0 \\
\hline & $\mathrm{X}^{2}$ & \multicolumn{6}{|c|}{1.491} \\
\hline & $\mathrm{P}$-value & \multicolumn{6}{|c|}{0.222} \\
\hline
\end{tabular}

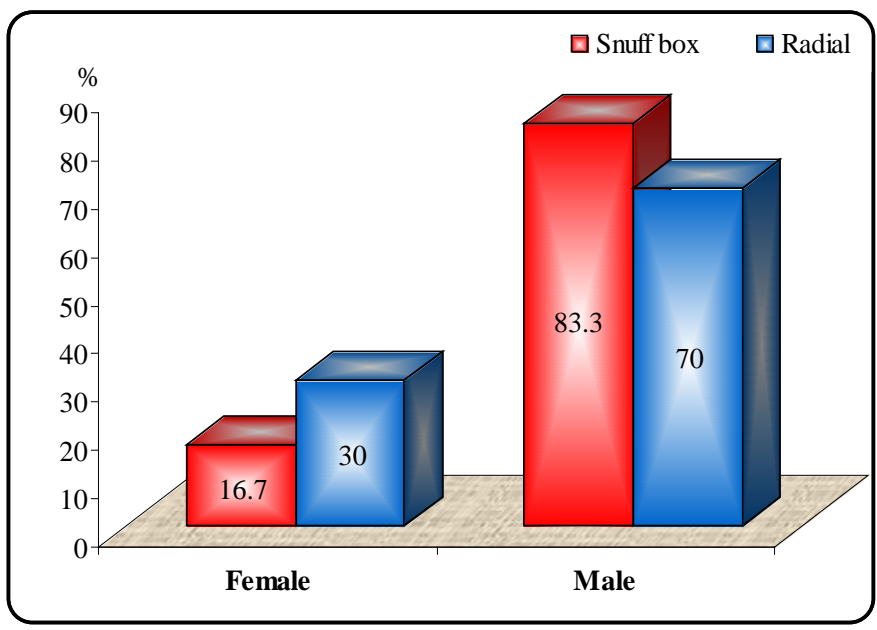

Figure 3. Comparison between two groups as regard gender. 
B: 6 were diabetic, 17 dyslipidemia and 7 hypertensive were as shown in Table 3.

There was no significant difference between two groups as regard $1^{\text {st }}$ cannulation attempts, in group, (A) 5 patients failed to be cannulated while in group (B) 3 patients failed to be cannulated also. There was no significant difference between the two groups as regard failure of cannulation. In group (A) 27 were successfully Cannulated with (3) failure of cannulation and this failure rate because of this new approach needs more experience, whereas 30 successfully cannulated members of the Group (B) due to higher experience of traditional radial artery cannulation as shown in Table 4.

Thrombosis higher significantly at group (B) with more thrombosis 8 cases in group (B) with monophasic wave in Doppler post procedure at the time of discharge, even 2 cases in group (A) with Monophasic wave in Doppler study after procedure at the time of discharge, Bleeding is more in group (B) 2 cases have bleeding in group (A) and need more long time of compression, in comparison with group (A) which 1 case have bleeding as shown in Table 5 and Figure 4.

Patient satisfaction is higher significant with group (A) (90\%) than group (B) (66.7\%) as shown in Table 6 and Figure 5.

Total duration of the procedure (totally 30 cases) in group (A) is $22.67 \pm 11.28$ minutes in comparison with group (B) (totally 30 cases) is $23.83 \pm 11.57$ minutes with non-significant difference between two groups as shown in Table 7.

In group (A) the time of discharge assessed after the procedure was $3.43 \pm$ $0.50 \mathrm{H}$, in comparison with the group (B) the time of discharge was $4.76 \pm 0.61$ $\mathrm{H}$, significantly shorter as time distributed in group $(\mathrm{A})$ as the time needed for compression is shorter than group (B) and this result with $\mathrm{P}$ value $<0.001^{\star}$ as shown in Table 8.

Table 3. Comparison between two groups as regard risk factor.

\begin{tabular}{ccccccc}
\hline & \multicolumn{9}{c}{ Groups } \\
\cline { 2 - 7 } Risk Factor & \multicolumn{2}{c}{$\begin{array}{c}\text { Snuff box } \\
\text { (Group A) }\end{array}$} & \multicolumn{2}{c}{$\begin{array}{c}\text { Radial } \\
\text { (Group B) }\end{array}$} & \multicolumn{2}{c}{ Chi-square } \\
\cline { 2 - 7 } & $\mathbf{N}$ & $\%$ & $\mathbf{N}$ & $\%$ & $\mathbf{X}^{2}$ & P-value \\
\hline DM & 5 & 16.7 & 6 & 20.0 & 0.111 & 0.739 \\
Dyslipidimc & 18 & 60.0 & 17 & 56.7 & 0.069 & 0.793 \\
HTN & 7 & 23.3 & 7 & 23.3 & 0.000 & 1.000 \\
\hline
\end{tabular}

Table 4. Failure of arterialcannulation distribution between groups.

\begin{tabular}{ccccccc}
\hline Failure & \multicolumn{3}{c}{ Groups } \\
& $\begin{array}{c}\text { Snuffbox } \\
\text { (Group A) }\end{array}$ & $\begin{array}{c}\text { Radial } \\
\text { (Group B) }\end{array}$ & & Chi-square \\
& $\mathrm{N}$ & $\%$ & $\mathrm{~N}$ & $\%$ & $\mathrm{X} 2$ & P-value \\
Failure of $1^{\text {st }}$ cannulation & 5 & 16.67 & 3 & 10 & 0.144 & 0.704 \\
Failure of cannulation & 3 & 10 & 0 & 0 & 1.404 & 0.236 \\
\hline
\end{tabular}


Table 5. Comparison between two groups as regard complication.

\begin{tabular}{ccccccc}
\hline & \multicolumn{9}{c}{ Groups } \\
\cline { 2 - 8 } Complication & \multicolumn{2}{c}{$\begin{array}{c}\text { Snuff box } \\
\text { (Group A) }\end{array}$} & \multicolumn{2}{c}{$\begin{array}{c}\text { Radial } \\
\text { (Group B) }\end{array}$} & \multicolumn{2}{c}{ Chi-square } \\
\cline { 2 - 8 } & $\mathbf{N}$ & $\%$ & $\mathbf{N}$ & $\%$ & $\mathbf{X}^{2}$ & P-value \\
\hline Non complicated & 26 & 86.7 & 20 & 66.7 & 3.54 & 0.067 \\
Thrombosis & 2 & 6.7 & 8 & 26.7 & 4.320 & 0.03 \\
Bleeding & 1 & 3.3 & 2 & 6.7 & 0.351 & 0.554 \\
Infection & 1 & 3.3 & 0 & 0.0 & 1.017 & 0.313 \\
\hline
\end{tabular}

Table 6. Comparison between two groups as regard patient satisfaction.

\begin{tabular}{|c|c|c|c|c|c|c|c|}
\hline \multirow{3}{*}{\multicolumn{2}{|c|}{ Patient Satisfaction }} & \multicolumn{6}{|c|}{ Groups } \\
\hline & & \multicolumn{2}{|c|}{$\begin{array}{c}\text { Snuff box } \\
\text { (Group A) }\end{array}$} & \multicolumn{2}{|c|}{$\begin{array}{c}\text { Radial } \\
\text { (Group B) }\end{array}$} & \multicolumn{2}{|c|}{ Total } \\
\hline & & $\mathbf{N}$ & $\%$ & $\mathbf{N}$ & $\%$ & $\mathrm{~N}$ & $\%$ \\
\hline \multicolumn{2}{|c|}{ Not } & 3 & 10.0 & 10 & 33.3 & 13 & 21.7 \\
\hline \multicolumn{2}{|c|}{ Satisfied } & 27 & 90.0 & 20 & 66.7 & 47 & 78.3 \\
\hline \multicolumn{2}{|c|}{ Total } & 30 & 100.0 & 30 & 100.0 & 60 & 100.0 \\
\hline \multirow{2}{*}{ Chi-square } & $\mathrm{X}^{2}$ & \multicolumn{6}{|c|}{4.812} \\
\hline & $\mathrm{P}$-value & \multicolumn{6}{|c|}{$0.028^{*}$} \\
\hline
\end{tabular}

Table 7. Comparison between two groups as regard duration.

\begin{tabular}{|c|c|c|c|c|c|c|c|c|}
\hline \multirow{2}{*}{ Groups } & \multicolumn{6}{|c|}{ Duration (Minute) } & \multicolumn{2}{|c|}{ T-test } \\
\hline & & Range & & Mean & \pm & SD & $\mathrm{t}$ & $P$-value \\
\hline $\begin{array}{l}\text { Snuff box } \\
\text { (Group A) }\end{array}$ & 10 & - & 44 & 22.67 & \pm & 11.28 & & \\
\hline $\begin{array}{c}\text { Radial } \\
\text { (Group B) }\end{array}$ & 10 & - & 45 & 23.83 & \pm & 11.57 & 0.395 & 0.694 \\
\hline
\end{tabular}

Table 8. Comparison between two groups as regard discharge time.

\begin{tabular}{|c|c|c|c|c|c|c|c|c|}
\hline \multirow{2}{*}{ Groups } & \multicolumn{6}{|c|}{ Discharge time (Hours) } & \multicolumn{2}{|c|}{ T-test } \\
\hline & & Range & & Mean & \pm & SD & $\mathrm{t}$ & $\mathrm{P}$-value \\
\hline $\begin{array}{l}\text { Snuff box } \\
\text { (Group A) }\end{array}$ & 3 & - & 4 & 3.43 & \pm & 0.50 & & \\
\hline $\begin{array}{c}\text { Radial } \\
\text { (Group B) }\end{array}$ & 4 & - & 6 & 4.67 & \pm & 0.61 & 8.566 & $<0.001^{\star *}$ \\
\hline
\end{tabular}

\section{Discussion}

Radial access for coronary and peripheral interventional angiography has dramatically increased worldwide since its introduction in 1989 by Campeau. Interventional cardiology studies comparing a transradial approach (TRA) with a transfemoral approach (TFA) have shown an unequivocal benefit of the former, 


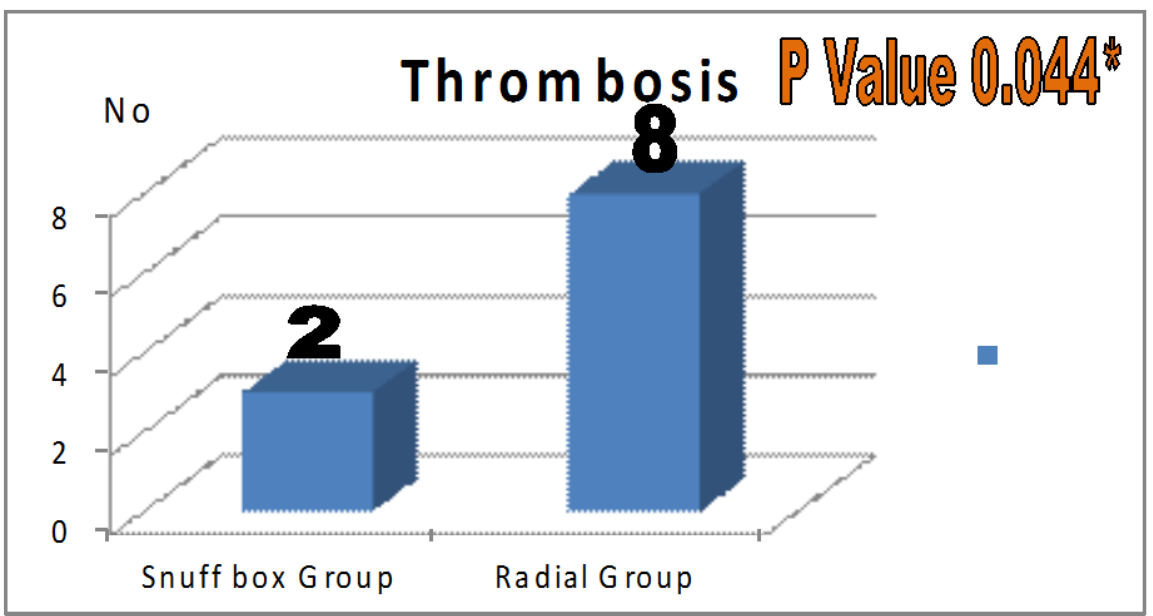

Figure 4. Thrombosis COMPLICATION (RAO) distribution between groups.

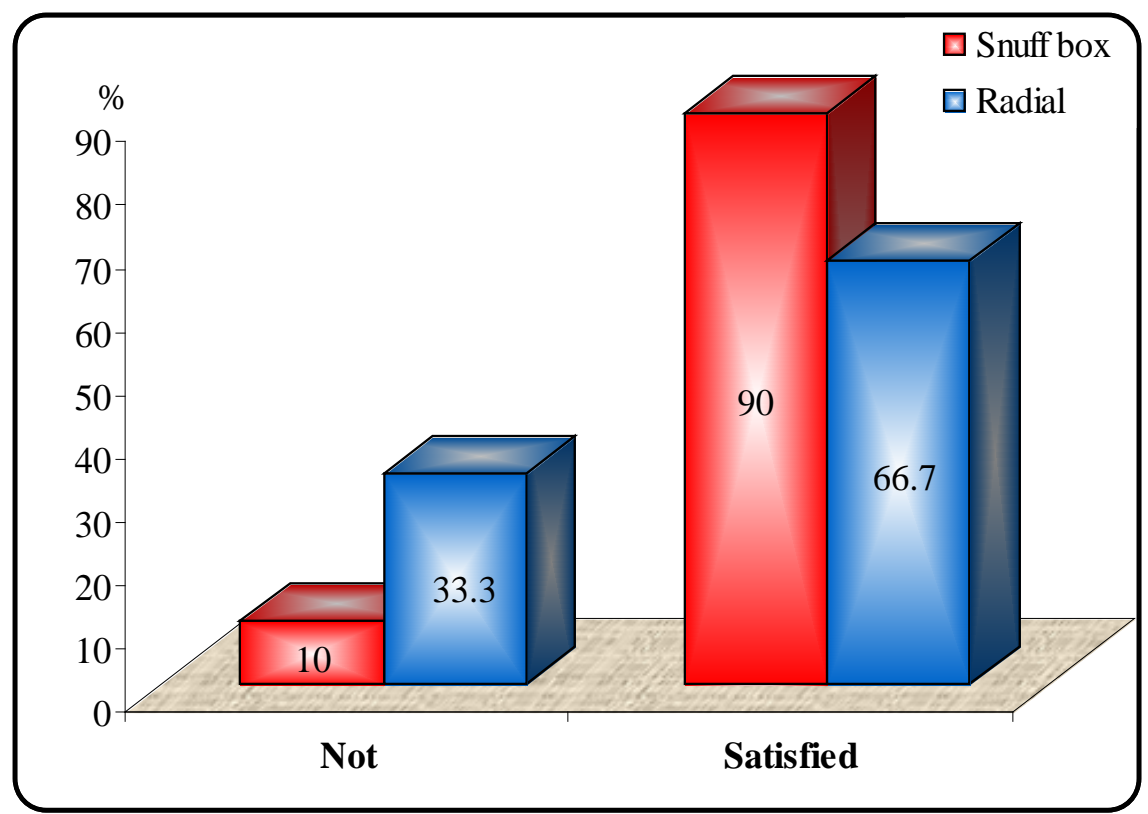

Figure 5. Comparison between two groups as regard patient satisfaction.

with reduced morbidity and mortality, greater patient preference, and cost reductions [14].

Performing the endovascular interventions via forearm radial artery (FRA) is considered preferable due to the lower risk of access site bleeding his is caused by anatomical proximity of the radial artery to the "bone basement" [15].

Interventional cardiologists have recently begun to adopt a modification of TRA, the distal transradial approach (dTRA), for coronary interventions. A rare minor complication of TRA is radial artery occlusion (RAO), a clinically silent complication that occurs in approximately $4 \%$ of patients [16].

Repeated transradial procedures may increase the occurrence of arterial occlusion and limit the viability of the vessel as an access site for further procedures or grafting. The dTRA confers theoretical improvements in preservation 
of the radial artery, as well as ease of left-sided catheterization, and improved patient-operator ergonomics. More importantly, this segment of the radial artery is distal to the origin of the superficial palmar branch, which supplies numerous palmar collaterals to the deep palmar arch. Puncture at this site preserves palmar collaterals, decreasing the risk of ischemic hand events even in cases of post procedural arterial occlusion at the access site. Preliminary cardiology results have shown technical and procedural success and no access-site complications [17].

The anatomical snuffbox is a depressed space located in the radial part of the wrist and surrounded laterally by the tendons of the abductor pollicis longus and extensor pollicis brevis muscles and medially by the tendon of the extensor pollicis longus muscle. Although the rate of RAO in standard TRA is low (1\% - 6\%) and nearly always asymptomatic, rare cases of hand ischemia have been described in the setting of inadequate ulnar collateral circulation, as well as symptoms of pain or paresthesias at the site of the arterial occlusion [18].

Additionally chronic RAO or intimal damage to the radial artery can limit future transradial access as well as use of the radial artery as a conduit for bypass grafting or arteriovenous fistula formation. Puncture distal to the origin of the superficial palmar branch of the radial artery diminishes the risk of ischemic events in the setting of RAO, because post procedural RAO typically occurs at the site of puncture. Owing to bifurcation of the radial artery, in ITRA the superficial palmar branch is preserved and allows for adequate perfusion of the hand even in the event of distal radial RAO Furthermore, RAO in the distal radial artery does not limit future interventions via a traditional TRA or surgical grafting [19].

Feasibility and safety of this technique initially provoked some euphoria among some interventional specialists, but later there was a realization of disadvantages of Radial artery catheterization including radial artery spasm, vessel thrombosis and different types of wall lesions of the access artery, The common place for radial artery catheterization is forearm at its distal third, but another site to puncture the radial artery is located within the anatomical snuffbox, and distally, at the dorsal Han faced sur, in the vertex of the angle between the long extensor of the thumb and the second metacarpal bone. Radial artery catheterization within the anatomical snuffbox followed by hemostasis allows preserving distal blood flow in the superficial palmar arch thus reducing the risk of occlusion of the access artery. Moreover, this approach also reduces the risk of redundant compression with following occlusion of the access artery [19].

That is why the study was selected to be conducted to reduce the rate of access-related complications by compare between the Traditional radial access and new distal radial approach by history and Doppler investigation and follow up.

The main results of the study were as following:

Our study show that Out of the 60 patients, 25 (83\%) were male and $5(17 \%)$ 
were female in Snuff box Group whereas 21 (70\%) members of the Radial Group were male and $9(30 \%)$ were female. There was no significant difference between groups regarding sex. The mean \pm SD ages was distributed as $53.47 \pm 4.32$ years and $53.77 \pm 4.42$ years with no significant difference between groups also there was no significant difference between groups.

This agreement with study conducted by [20] who study Coronary angiography using the left distal radial approach-an alternative site to conventional radial coronary angiography and reported that mean age of patients was 59.3 years and $80 \%$ were male.

This coped that study conducted by [21] who reported that the mean \pm SD ages of studied group was distributed as $53.42 \pm 4.13$. Also this agreement with study is conducted by who reported that Male participants comprised $41.2 \%$ of the recruited participants.

In the present study regarding Risk Factor. Out of the 60 patients, 5 (17\%) were DM in Snuff box Group whereas 6 (20\%) members of the Radial Group, 18 (60\%) were Dyslipidemia indistal radial Group whereas 17 (57\%) members of the Radial Group and 7 (23\%) were HTN in distal radial Group whereas 7 (23\%) members of the Radial Group.

This agreement with study conducted by [20] who reported that Hypertension and diabetes mellitus were the most frequent risk factors for cardiovascular disease, with rates of $61.1 \%$ and $33.3 \%$ respectively.

Data on distal radial access remain limited in both the cardiology and neuro interventional literature. Failure rates requiring cross over to either TRA or TFA is reported to be between $0.3 \%$ and $11 \%$ [22].

In the present study regarding Failure rate distribution between groups. Out of the 60 patients, 27 (90\%) were no Failure in distal radial Group whereas at radial group $30(100 \%)$ members without failure of cannulation.

[23] Reported that access was suitable in 195 patients with a success rate of 89.4\%. In 9 patients arterial puncture failed, while in 14 others despite successful arterial puncture the wire could not be advanced towards the forearm part of the radial artery.

[24] reported that The overall failure attempt incidence was $10.2 \%$ and the mean puncture time $3.9 \pm 4.1 \mathrm{~min}$. Angiography only was performed in $81.8 \%$ and angiography followed by percutaneous coronary intervention in $18.2 \%$ of the patients.

[25] Reported that the successive use of the same radial artery is associated with a cannulation failure rate of $3.5 \%$ and $7.9 \%$ in men and women, at the second attempt, rising to $30 \%$ and $50 \%$ at the 5 th attempt, respectively.

The present study showed that duration was distributed as $22.4 \pm 7.03$ and $23.0 \pm 7.2$ with no significant difference between groups.

The present study showed that Thrombosis was higher significant with radial group (2.7\%) than distal radial group (6.7\%).

Although occurrence of RAO depends on various factors, including heparin dose, sheath size, vasodilator use, and hemostatic events, recent studies have 
suggested that damage to the arterial wall and subsequent changes including medial dissection, intimal tear, and thrombus formation are predominantly observed at the puncture site [26] [27]. This may contribute to the subsequent retrograde thrombus formation and total occlusion of the radial artery [25].

One randomized study of 200 patients demonstrated no significant difference in rates of RAO after dTRA versus TRA for coronary intervention (5\% dTRA vs $9 \%$ TRA, $\mathrm{p}=0.407)$. However, in a study of 1320 patients who underwent right dTRA for coronary intervention, late RAO was observed in only $0.61 \%$ of cases [19].

[20] reported that Owing to the clear safety benefits of transradial access, our center uses a default traditional transradial approach for diagnostic angiography. However, recent reports in the interventional cardiology literature have suggested additional advantages of decreased rates of RAO and ischemic hand events, as well as improved ergonomics with distal transradial artery access in the "snuffbox".

The present study showed that Bleeding was none significantly between radial group $6.7 \%$ and distal radial group $3.3 \%$.

[24] Reported that Manual hemostasis was applied in $63.6 \%$ of the patients, which had a significantly shorter duration than device hemostasis (11 \pm 7 versus $198 \pm 42 \mathrm{~min}, \mathrm{p}<0.001)$. No distal or forearm radial artery occlusion was observed on triplex ultrasonography $24 \mathrm{~h}$ after successful hemostasis. No major complications were recorded.

The present study showed that discharge time Shorter in distal radial Group significantly $3.43 \pm 0.50$ hours versus radial group $4.67 \pm 0.61$ hours.

This agree and Further benefits cited for snuff box access include shorter discharge times due to statistically significant decreases in the time needed for radial artery compression (69 min less than traditional radial puncture for punctures in the snuff box in patients undergoing cardiac interventions). As of 2018, only 200 snuff box radial access cases had been described and predominately in the cardiac literature [13].

The present study showed that patients Satisfaction more in distal radial Group (90\%) and (66.7\%) in radial group.

[25] Found that slightly higher rates of patient satisfaction in the dTRA group than in the TRA group, although this difference was not significant.

\section{Conclusion and Recommendation}

Coronary procedures by distal radial approach have minor access complication versus the conventional transradial approach.

So the present study recommends that the cardiac intervention from distal radial artery access more benefits, less incidence of complication. Also we found we can do Coronary angiography and intervention from anatomical snuff box access.

Further long-term studies will be needed for a more accurate assessment of 
procedure-related complications.

\section{Limitation}

The study was performed at a single center with a relatively small study population. Different operators with variable skills, Financial issues also limit the increasing the population of the study.

\section{Conflicts of Interest}

The authors declare no conflicts of interest regarding the publication of this paper.

\section{References}

[1] Lam, M.K., Sen, H., Tandjung, K., et al. (2014) Comparison of 3 Biodegradable Polymer and Durable Polymer-Based Drug-Eluting Stents in All-Comers (BIO-RESORT): Rationale and Study Design of the Randomized TWENTE III Multicenter Trial. American Heart Journal, 167, 445-451. https://doi.org/10.1016/j.ahj.2013.11.014

[2] De Man, F.H.A.F., Tandjung, K., Hartmann, M., et al. (2012) Usefulness and Safety of the GuideLiner Catheter to Enhance Intubation and Support of Guide Catheters: Insights from the Twente GuideLiner Registry. EuroIntervention, 8, 336-344. https://doi.org/10.4244/EIJV8I3A52

[3] Bertrand, O.F., Bélisle, P., Joyal, D., et al. (2012) Comparison of Transradial and Femoral Approaches for Percutaneous Coronary Interventions: A Systematic Review and Hierarchical Bayesian Meta-Analysis. American Heart Journal, 163 , 632-648. https://doi.org/10.1016/j.ahj.2012.01.015

[4] Jolly, S.S., Amlani, S., Hamon, M., Yusuf, S. and Mehta, S.R. (2009) Radial versus Femoral Access for Coronary Angiography or Intervention and the Impact on $\mathrm{Ma}$ jor Bleeding and Ischemic Events: A Systematic Review and Meta-Analysis of Randomized Trials. American Heart Journal, 157, 132-140. https://doi.org/10.1016/j.ahj.2008.08.023

[5] Kaledin, A., Kochanov, I., Podmetin, P. and Seletsky, S.S. (2017) Distal Radial Artery in Endovascular Interventions.

[6] Talamonti, M., Galluzzo, M., Bernardini, N., et al. (2018) Psoriasis Area and Severity Index Response in Moderate-Severe Psoriatic Patients Switched to Adalimumab: Results from the OPPSA Study. Journal of the European Academy of Dermatology and Venereology, 32, 1737-1744. https://doi.org/10.1111/jdv.15077

[7] Elshafey, A.M., Montaser, S.S., Mena, M.P. and Abd El-mageed, A.A. (2015) Safety and Efficacy of Transradial versus Transfemoral Approach in Caplasty for Myocardial Infarction. Master Thesis, Menoufia University, Faculty of Medicine, Al Minufya.

[8] Kaledin, A. (2014) New Access to Facilitate Endovascular Operations: First-in-Man Study.

[9] Cerda, A. and del Sol, M. (2015) Anatomical Snuffbox and It Clinical Significance: A Literature Review. International Journal of Morphology, 33, 1355-1360. https://doi.org/10.4067/S0717-95022015000400027

[10] Vilela, F.D., Boechat e Salles, J.A., Cortes, L.A., Ferreira da Costa, G.B. and Manso Vieira, W.J. (2017) Distal Transradial Access in the Anatomical Snuffbox for Coronary Angiogrophy and Aortography. Journal of Anatomy and Physiological Studies, 
$1,1-13$.

[11] Doscher, W., Viswanathan, B., Stein, T. and Margolis, I.B. (1983) Hemodynamic Assessment of the Circulation in 200 Normal Hands. Annals of Surgery, 198, 776. https://doi.org/10.1097/00000658-198312000-00018

[12] Gupta, S. and Nathan, S. (2015) Radial Artery Use and Reuse. Cardiac Interventions Today, 9, 49-56.

[13] Coughlan, J.J., Zebrauskaite, A., Arnous, S. and Kiernan, T.J. (2018) Left Distal Trans-Radial Access Facilitates Earlier Discharge Post-Coronary Angiography. Journal of Interventional Cardiology, 31, 964-968.

https://doi.org/10.1111/joic.12559

[14] Mamas, M., Tosh, J., Hulme, W., et al. (2018) Health Economic Analysis of Access Site Practice in England during Changes in Practice: Insights from the British Cardiovascular Interventional Society. Circulation: Cardiovascular Quality and Outcomes, 11, e004482. https://doi.org/10.1161/CIRCOUTCOMES.117.004482

[15] Hamon, M., Pristipino, C., Di Mario, C., et al. (2013) Consensus Document on the Radial Approach in Percutaneous Cardiovascular Interventions: Position Paper by the European Association of Percutaneous Cardiovascular Interventions and Working Groups on Acute Cardiac Care and Thrombosis of the European Society of Cardiology. EuroIntervention, 8, 1242-1251. https://doi.org/10.4244/EIJV8I11A192

[16] Sinhas, K., Jha, M.J., Mishra, V., et al. (2017) Radial Artery Occlusion-Incidence, Predictors and Long-Term Outcome after Transradial Catheterization: Clinico-Doppler Ultrasound-Based Study (RAIL-TRAC Study). Acta Cardiologica, 72, 318-327. https://doi.org/10.1080/00015385.2017.1305158

[17] Valsecchi, O., Vassileva, A., Ceredaa, F., et al. (2018) Early Clinical Experience with Right and Left Distal Transradial Access in the Anatomical Snuffbox in 52 Consecutive Patients. Journal of Invasive Cardiology, 30, 218-223.

[18] Caputo, R.P., Tremmel, J.A., Rao, S., et al. (2011) Transradial Arterial Access for Coronary and Peripheral Procedures: Executive Summary by the Transradial Committee of the SCAI. Catheterization and Cardiovascular Interventions, 78, 823-839. https://doi.org/10.1002/ccd.23052

[19] Kaledina, L., Kochanovi, N., Seletskiǔss, et al. (2014) Peculiarities of Arterial Access in Endovascular Surgery in Elderly Patients. Advances in Gerontology, 27, 115-119.

[20] Soydan, E. and Akın, M. (2018) Coronary Angiography Using the Left Distal Radial Approach-An Alternative Site to Conventional Radial Coronary Angiography. The Anatolian Journal of Cardiology, 19, 243-248. https://doi.org/10.14744/AnatolJCardiol.2018.59932

[21] Brunet, M.C., Chen, S.H., Sur, S., McCarthy, D.J., Snelling, B., Yavagal, D.R., Peterson, E.C., et al. (2019) Distal Transradial Access in the Anatomical Snuffbox for Diagnostic Cerebral Angiography. Journal of NeuroInterventional Surgery, 11, 710-713. https://doi.org/10.1136/neurintsurg-2019-014718

[22] Kok, M.M., Weernink, M.G.M., von Birgelen, C., et al. (2018) Patient Preference for Radial versus Femoral Vascular Access for Elective Coronary Procedures: The PreVas Study. Catheterization and Cardiovascular Interventions, 91, 17-24. https://doi.org/10.1002/ccd.27039

[23] Wretowski, D., Krakowian, M., Łabyk, A., Pruszczyk, P. and Roik, M. (2019) Very Distal Transradial Approach (VITRO) for Coronary Interventions. Postępy w Kardiologii Interwencyjnej, 15, 42. https://doi.org/10.5114/aic.2019.83771

[24] Ziakas, A., Koutouzis, M., Didagelos, M., Tsiafoutis, I., Kouparanis, A., Gossios, T., 
Karvounis, H., et al. (2018) Right Arm Distal Transradial (Snuffbox) Access for Coronary Catheterization: Initial Experience. Hellenic Journal of Cardiology, 61, 106-109.

[25] Mizuguchi, Y., Izumikawa, T., Hashimoto, S., Yamada, T., Taniguchi, N., Nakajima, S., Takahashi, A., et al. (2019) Efficacy and Safety of the Distal Transradial Approach in Coronary Angiography and Percutaneous Coronary Intervention: A Japanese Multicenter Experience. Cardiovascular Intervention and Therapeutics, 24, 1-6. https://doi.org/10.1007/s12928-019-00590-0

[26] Yonetsu, T., Kakuta, T., Lee, T., Takayama, K., Kawita, K., Iwamoto, T., et al. (2010) Assessment of Acute Injuries and Chronic Intimal Thickening of the Radial Artery after Transradial Coronary Intervention by Optical Coherence Tomography. European Heart Journal, 31, 1608-1615. https://doi.org/10.1093/eurheartj/ehq102

[27] Staniloae, C.S., Mody, K.P., Sanghvi, K., Mindrescu, C., Coppola, J.T., Antonescu, C.R., et al. (2009) Histopathologic Changes of the Radial Artery Wall Secondary to Transradial Catheterization. Vascular Health and Risk Management, 5, 527-532. https://doi.org/10.2147/VHRM.S5468. 